\title{
- Tumores em pele e partes moles de cães - Estudo clínico e cito-histológico
}

\section{- Canine skin and soft tissue tumors - Clinical and cytohistological study}

\section{- Tumores de piel y partes blandas en perros - Estudio clínico y citobistológico}

* Maria Carolina Catai Chalita ${ }^{1}$ - CRMV-SP - n 6710

Julia Maria Matera ${ }^{2}$ - CRMV-SP - $\mathbf{n}^{0} 1050$

Maria Teresa de Seixas Alves ${ }^{3}$ - CRM - n 62373

Adhemar Longatto Filho ${ }^{4}-$ CRBM - $\mathbf{n}^{0} 1209$

1 Mestre pelo Departamento de Cirurgia da FMVZ - USP.

2 Professor Titular do Departamento de Cirurgia da FMVZ-USP.

3 Professor Adjunto do Departamento de Patologia da UNIFESP.

4 Doutor pelo Departamento de Patologia da FMVZ-USP.

\section{RESUMO}

No período de agosto de 1998 a dezembro de 1999, 213 cães portadores de 300 tumores em pele e/ou partes moles foram avaliados clinicamente, e o material coletado das lesões, com uma agulha fina (21-27G), sem aspiração, foi submetido ao exame citológico. Os esfregaços foram secos ao ar e corados pela técnica de Rosenfeld. Cães com seis anos de idade ou mais ( $n=159)$ compreende$\operatorname{ram} 75 \%$ dos casos; $56 \%(n=119)$ dos animais eram do sexo masculino e $44 \%(n=94)$ do feminino. Animais sem raça definida (SRD) $(n=74)$, seguidos das raças Boxer $(n=21)$, Poodle $(n=18)$, Pastor Alemão $(n=15)$, Cocker Spaniel $(n=12)$ e Doberman $(n=11)$ foram os mais freqüentes. Quarenta por cento dos cães $(85 / 213)$ tiveram seus 117 tumores submetidos também ao exame histológico. Foram encontradas 77 lesões benignas ( 22 não-neoplásicas e 55 neoplásicas) e 40 malignas. Os tumores foram representados por lesões não-neoplásicas (19\%), neoplasia epitelial (36\%), neoplasia mesenquimal (30\%), neoplasia de célula redonda $(13 \%)$ e neoplasia melanocítica (2\%). As lesões não neoplásicas mais freqüentes foram os processos inflamatórios com granuloma tipo corpo estranho $(n=9)$ e os cistos epidérmicos $(n=9)$; dentre as neoplasias benignas, o lipoma $(n=14)$ e o tricoblastoma $(n=10)$ e, dentre as malignas, o mastocitoma $(n=14)$ e o hemangiopericitoma 


\section{RESUMO}

$(\mathrm{n}=9)$ foram as mais freqüentes. O método citológico demonstrou ser bastante eficaz na avaliação de tumores em pele e partes moles, com sensibilidade de $89 \%$, especificidade de $100 \%$, valor preditivo positivo de $100 \%$, valor preditivo negativo de $96 \%$, eficiência de $97 \%$ quando comparado ao exame histológico.

Palavras-chave: Neoplasia. Pele. Citologia. Histologia. Cães.

\section{INTRODUÇÃO}

$\underline{0}$ Os tumores na pele e partes moles estão entre os mais freqüentemente encontrados na espécie canina, representando aproximadamente um terço de todos aqueles que acometem esta espécie (BOSTOCK, 1986; DOBSON; GORMAN, 1988; GORMAN, 1996). As raças mais acometidas variam de acordo com a popularidade delas nos diversos países, embora os cães da raça Boxer estejam sempre bem representados nos diferentes estudos (MORIELLO; ROSENTHAL, 1990). Animais adultos (6-14 anos) são mais susceptíveis sendo a incidência proporcional à idade (ER; SUTTON, 1989; MORIELLO; ROSENTHAL, 1990), com exceção de neoplasias que afetam principalmente animais jovens, como o histiocitoma e os papilomas virais (PRIESTER, 1973; MORIELLO; ROSENTHAL, 1990). A incidência entre machos e fềmeas parece ser equivalente (CONROY, 1983; VAIL, WITHROW, 1996), principalmente se for desconsiderar os tumores de mama nas fềmeas e os da glândula hepatóide nos machos.

As neoplasias cutâneas podem estar localizadas na epiderme e/ou derme, acometendo as diversas estruturas que compõem a pele (BARTON, 1987). As neoplasias de partes moles (músculo, gordura, tecido fibroso, vasos e nervos) são definidas como proliferações mesenquimais originárias de tecido extraesquelético e não epitelial, além de excluir aqueles em vísceras, cérebro e sistema linfo-reticular (ENZINGER, 1995).

O diagnóstico freqüente das neoplasias em pele e partes moles representa o reflexo da maior probabilidade de observação precoce dessas lesões pelos proprietários e veterinários. Isto implica a maior eficácia no controle e tratamento dessas afecções, já que o diagnóstico precoce está intimamente relacionado ao prognóstico do paciente (BOSTOCK; OWEN, 1975; RUAUX, 1993).
Tumorações de origem variada podem-se apresentar clinicamente com aspecto similar, assim como um mesmo tipo de tumor pode se manifestar sob formas diversas. Isto reflete a impossibilidade da obtenção do diagnóstico preciso do processo somente com as informações obtidas na anamnese e no exame físico; "um tumor é apenas um tumor" até que seja examinado cito e histologicamente (MORIELLO; ROSENTHAL, 1990).

\section{REVISĀO DA LITERATURA}

O diagnóstico citológico das neoplasias referese à caracterização microscópica de células coletadas de uma formação tumoral ou efusão (WELLMAN, 1990). É um dos procedimentos diagnósticos mais utilizados nos casos de tumores em pele e nos tecidos moles (40). Representa um meio diagnóstico eficiente na Medicina Veterinária, pois não implica a necessidade de equipamento sofisticado, podendo ser realizada ambulatorialmente, além de ser um procedimento simples, barato, rápido, com pouco ou nenhum risco para o paciente (SCHULTENOVER et al., 1984; LEVER; TROTT; WEBB, 1985; MIRALLES et al., 1986; PHILIPS; GOODMAN, 1987; ELSE, 1989; TYLER et al., 1999).

A interpretação citológica auxilia no estabelecimento do diagnóstico, na identificação de processos inflamatórios ou neoplásicos, sendo possível, muitas vezes, a caracterização do tipo de inflamação e de possíveis agentes infecciosos associados ou a classificação histogenética das neoplasias, além de avaliar a presença ou não de malignidade (SEYBOLD; GOLDSTON; WILKES, 1982; BARTON, 1983; ALLEN; PRASSE, 1986; VALLI, 1988).

O diagnóstico citológico pode direcionar o tipo de tratamento pré-cirúrgico, cirúrgico, radioterápico ou quimioterápico, evitando também procedimentos diagnósticos desnecessários e arriscados (BOTTLES et al., 
1986; BARTON, 1987). A análise das margens cirúrgicas (ROGERS; BARTON; HABRON, 1996), a identificação de metástases e o monitoramento de possíveis recidivas (JACOBS, 1988) constituem também outras indicações para o uso da citologia.

A impossibilidade de definir a extensão exata de uma lesão e obter o diagnóstico definitivo em algumas delas faz com que a citologia seja utilizada conjuntamente e não como método substituto ao histológico (URBACH; BURKE; TRAENKLE, 1957). O exame histopatológico é de extrema importância no diagnóstico, no planejamento da terapia e na determinação do prognóstico. Permite avaliar o grau de malignidade e invasão, além de verificar a presença ou não de resquícios neoplásicos nas bordas de uma peça retirada cirurgicamente (VAIL; WITHROW, 1996). Oferece freqüentemente um diagnóstico definitivo, mas com uma técnica mais trabalhosa e demorada, além do risco anestésico, de hemorragia e de infecção (LARKIN, 1994). A vantagem principal de seu uso é a preservação da arquitetura tecidual, necessária para a correlação do tipo neoplásico com o seu comportamento biológico e resposta à terapia (JACOBS, 1988).

Os resultados satisfatórios da citologia dependem da coleta de amostra adequada, do seu preparo e coloração correto, além do exame citológico minucioso. Um descuido em qualquer uma dessas etapas poderá comprometer o resultado final (REPPAS; CANFIELD, 1995).

\section{Coleta}

Várias técnicas de coleta do material para o exame citológico são conhecidas e a escolha de cada uma delas dependerá das características da lesão e da preferência do clínico (PERMAN; ALSAKER; RIIS, 1979; CAMPBELL, 1990). Em se tratando de lesões palpáveis, como é o caso dos tumores em pele e tecido subcutâneo, a técnica mais indicada é a coleta de material com agulha fina (VALLI, 1988; COWELL; TYLER, 1989; MORIELLO; ROSENTHAL, 1990). Ela permite tanto a coleta da amostra em região abaixo da área inflamada ou ulcerada como de lesões cobertas por pele normal (COWELL; TYLER, 1989).

A técnica sem aspiração, também conhecida por "técnica da sucção capilar"ou "citopunção" (SANTOS; LEIMAN, 1988), é feita apenas com a agulha, sem sucção. Promove menor trauma ao tecido, menor contaminação sangüínea da amostra e oferece uma melhor sensação tátil da lesão (VILLIERS; DUNN, 1998).

\section{Esfregaço}

A amostra citológica ideal é aquela fina, cujas células apresentam-se em uma monocamada onde o corante pode penetrar uniformemente (MEYER; FRANKS, 1986). As lâminas devem ser novas, estarem limpas e de preferência terem uma extremidade fosca para a rápida identificação a lápis do material (O'ROURKE, 1983).

O esfregaço do material coletado de lesões sólidas é preferencialmente preparado sob a forma de "squash", em que uma lâmina com o material coletado é sobreposta delicadamente à outra até que esse material se espalhe formando uma fina camada, impedindo sempre que ele alcance os bordos das lâminas. Em seguida, ambas as lâminas são deslizadas em direção oposta e como resultado temos dois esfregaços (COWELL; TYLER, 1989).

\section{Coloração}

Quanto à coloração empregada, a de Romanowsky (hematológica) é indicada por permitir a visualização de detalhes nucleares e citoplasmáticos de forma excelente e também por corar bactérias e fungos, além de inclusões e grânulos (HALL; MACWILLIAMS, 1988; VILLIERS; DUNN, 1998).

\section{MATERIAL E MÉTODO}

Foram atendidos 213 cães encaminhados ao Serviço de Cirurgia do Hospital Veterinário da Faculdade de Medicina Veterinária e Zootecnia da Universidade de São Paulo, no período de agosto de 1998 a dezembro de 1999. O material utilizado para o exame citológico foi colhido com agulha fina $(21 \mathrm{G}-27 \mathrm{G})$, sem aspiração. Quanto maior a lesão, maior foi o número de coletas realizadas, visando sempre a obtenção de material que representasse toda a formação. Com o auxílio de uma seringa de $10 \mathrm{ml}$, o material presente na agulha foi expelido em lâminas para a realização dos esfregaços. As lâminas foram secas ao ar, fixadas em metanol por 5 minutos e coradas por 20 minutos com o corante hematológico de Rosenfeld (May-GrünwaldGiemsa eágua bidestilada fervida, na proporção de 1:2). Ao término dessa etapa, as lâminas foram lavadas com água destilada e, quando secas, examinadas ao microscópio de luz.

Foi realizado o tratamento cirúrgico em 85 animais (40\%), dos quais se coletou o material para a avaliação histológica, necessária para a comparação 
citológica dos tumores. Todos os espécimes cirúrgicos analisados foram enviados ao Departamento de Patologia da Universidade Federal do Estado de São Paulo (UNIFESP), previamente fixados em formol a $10 \%$. Fragmentos representativos foram submetidos ao estudo histológico após serem devidamente preparados, cortados e corados pela Hematoxilina-Eosina.

\section{RESULTADOS}

Realizou-se análise citológica de 300 lesões em pele e partes moles de 213 cães, dos quais $119(56 \%)$ eram machos e $94(44 \%)$ fêmeas. Animais sem raça

\begin{tabular}{|c|c|c|c|c|c|c|c|c|c|c|c|}
\hline \multicolumn{12}{|c|}{ DIAGNÓSTICO HISTOLÓGICO } \\
\hline & \multicolumn{2}{|c|}{$\begin{array}{c}\text { Não } \\
\text { Neoplásico }\end{array}$} & \multicolumn{2}{|c|}{$\begin{array}{l}\text { Neoplasia } \\
\text { Epitelial }\end{array}$} & \multicolumn{2}{|c|}{$\begin{array}{l}\text { Neoplasia } \\
\text { Mesenquimal }\end{array}$} & \multicolumn{2}{|c|}{$\begin{array}{c}\mathrm{Neo}^{(1)} \text { Célula } \\
\text { Redonda }\end{array}$} & \multicolumn{2}{|c|}{$\begin{array}{c}\text { Neoplasia } \\
\text { Melanocitica }\end{array}$} & \multirow[t]{2}{*}{ Total } \\
\hline $\begin{array}{l}\text { Diagnóstico } \\
\text { Citológico }\end{array}$ & Pos & Neg & Pos & Neg & Pos & Neg & Pos & Neg & Pos & Neg & \\
\hline POSITIVO & - & - & 02 & - & 06 & - & 14 & - & 03 & - & 25 \\
\hline SUSPEITO & - & - & 03 & 01 & 08 & - & - & - & - & - & 12 \\
\hline NEGATIVO & - & 20 & 03 & 32 & - & 17 & - & 01 & - & - & 73 \\
\hline INADEQUADO & - & 02 & - & 01 & 01 & 03 & - & - & - & - & 07 \\
\hline Total & 0 & 22 & 08 & 34 & 15 & 20 & 14 & 01 & 03 & 0 & 117 \\
\hline (1) $\mathrm{Neo}=$ Neopla & & & & & & & & & & & \\
\hline
\end{tabular}

Quadro 1 - Correlação dos 117 tumores segundo o diagnóstico citológico e histológico, nos grupos não neoplásicos e neoplásicos epiteliais, mesenquimais, de células redondas e melanocíticos., São Paulo - agosto 1998-dezembro 1999

definida foram os mais freqüentes $(n=74)$, seguidos dos cães das raças Boxer $(n=21)$, Poodle $(n=18)$, Pastor Alemão $(n=15)$, Cocker Spaniel $(n=12)$ e Doberman $(n=11)$. As demais raças tiveram representatividade bem menor quando comparada às mais freqüentes acima citadas. Atendemos $54(25,5 \%)$ cães com até 5 anos de idade, 103 (48\%) entre 6 e 10 anos e 56 (26\%) com idade igual ou superior a 11 anos.

As lesões compreenderam $36 \%$ dos casos com até $2 \mathrm{~cm}$ de diâmetro, $35 \%$ entre 2 e $5 \mathrm{~cm}$ e $29 \%$ maiores ou iguais a $5 \mathrm{~cm}$.

Foram avaliados 85 cães (117 tumores) pelo exame citológico e histológico. Cinqüenta e sete lesões $(49 \%)$ estavam localizadas na região do tronco, 31 (27\%) nos membros, $11(9 \%)$ eram cefálicas, $9(8 \%)$ na região perianal, $5(4 \%)$ eram cervicais e $4(3 \%)$ em bolsa testicular.

No estudo citopatológico dos 117 tumores, foram encontrados 25 casos positivos, todos eles confirmados na histologia. Foram obtidos 73 casos negativos e, dentre eles, 70 foram histologicamente comprovados como benignos. Dos 12 considerados suspeitos, 11 eram positivos e 1 negativo. $\mathrm{O}$ resultado inadequado ocorreu em 7 citologias (taxa de aproveitamento de $94 \%$ ), das quais 6 negativas e 1 positiva para malignidade. Na avaliação histológica, 40 (34\%) tumores foram positivos para malignidade e $77(66 \%)$ negativos para malignidade. Havia 22 (19\%) lesões nãoneoplásicas, 42 (36\%) neoplasias de origem epitelial, $35(30 \%)$ neoplasias de origem mesenquimal, $15(13 \%)$ neoplasias de célula redonda e $3(2 \%)$ melanocíticas (Quadro 1).

As lesões não-neoplásicas corresponderam a 9 (41\%) processos inflamatórios (Figura 1), 9 (41\%) cis- tos epidérmicos, $2(9 \%)$ hiperplasias epiteliais, $1(4,5 \%)$ proliferação fibroepitelial reacional e $1(4,5 \%)$ cisto com proliferação epitelial.

Dentre as 55 neoplasias benignas, havia 34 (62\%) epiteliais, $20(36 \%)$ mesenquimais, 1 (2\%) de célula redonda. As epiteliais foram representadas por tricoblastoma $(n=10)$, adenoma hepatóide $(n=6)(F i-$ gura 2), pilomatrixoma $(n=6)$, tricoepitelioma $(n=5)$, adenoma sebáceo $(n=3)$, cistoadenoma apócrino $(n=2)$, adenoma pleomórfico $(\mathrm{n}=1)$, adenoma de glândula apócrina $(\mathrm{n}=1)$. Dentre as neoplasias mesenquimais, havia lipoma $(n=14)$, hemangioma $(n=3)$, fibroma $(n=2)$, neoplasia mesenquimal sem outra especificação $(n=1)$. O único caso de neoplasia benigna de célula redonda foi o histiocitoma (Figura 3).

As 40 neoplasias malignas foram representadas por $15(37,5 \%)$ neoplasias de origem mesenquimal, 14 (35\%) neoplasias de célula redonda, $8(20 \%)$ neoplasias de origem epitelial e $3(7,5 \%)$ melanocíticas. As neoplasias mesenquimais malignas foram o hemangiopericitoma $(n=9)$ (Figura 4), o fibrohistiocitoma maligno $(n=2)$, o lipossarcoma $(n=2)$, o fibrossarcoma ( $\mathrm{n}=1)$ e sarcoma sem outra especificação $(\mathrm{n}=1)$. A neoplasia maligna de células redondas foi o mastocitoma $(n=14)$ e as epiteliais foram epitelioma sebáceo $(n=3)$, tricoepitelioma maligno $(n=2)$, carcinoma $(n=2)$, e carcinoma de glândula hepatóide $(n=1)$. Houve 3 casos de neoplasia melanocítica.

O método citológico apresentou sensibilidade de $89 \%$, especificidade de $100 \%$, valor preditivo positivo de $100 \%$, valor preditivo negativo de $96 \%$ e eficiência de $97 \%$, quando comparado ao exame histológico das 117 lesões. 

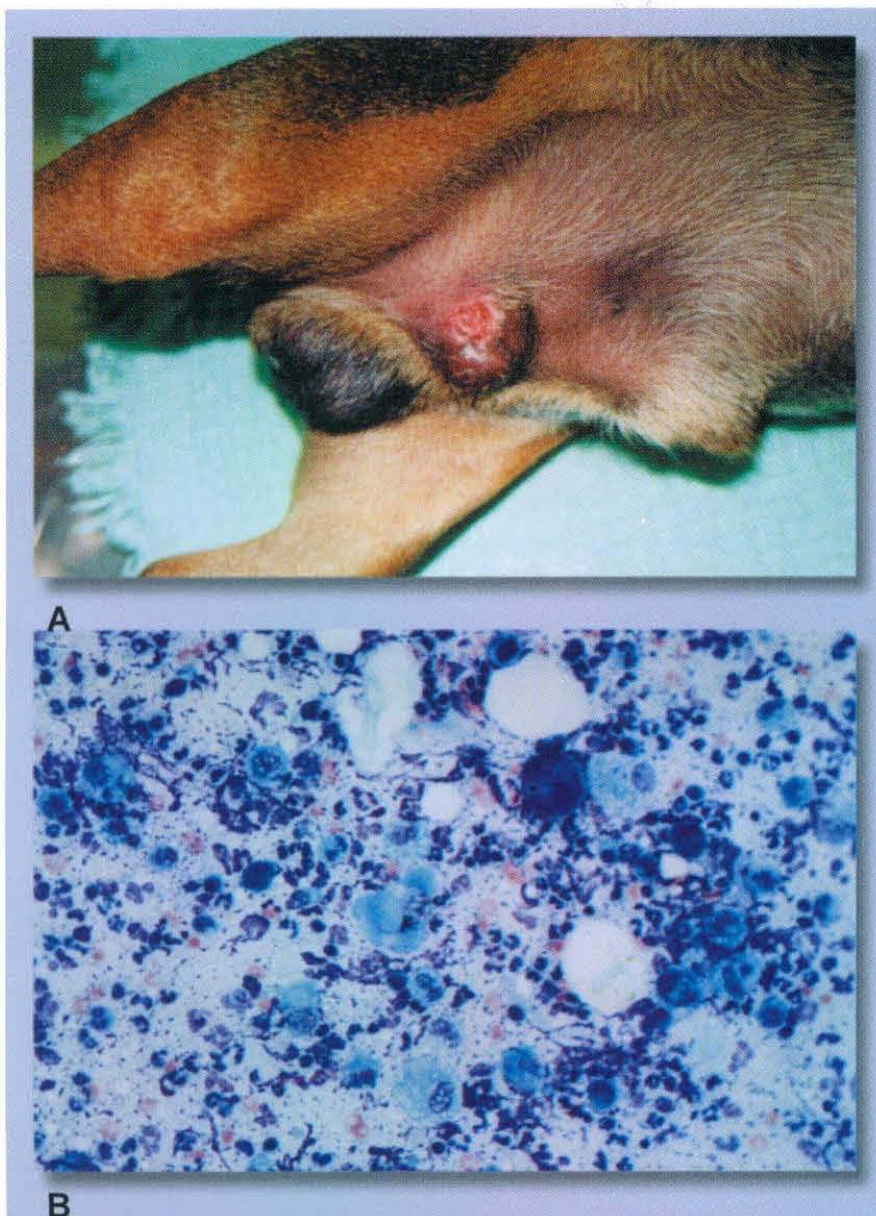

\section{B}

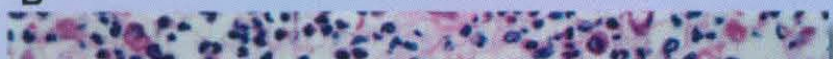
2.

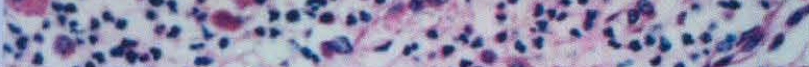

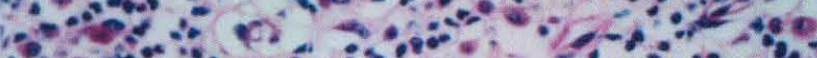
1 ec* 1.

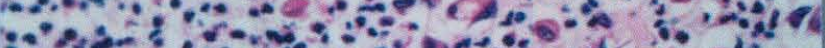

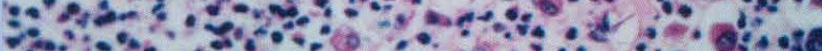

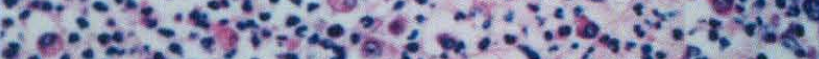

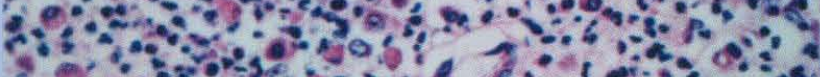

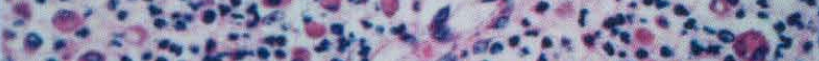

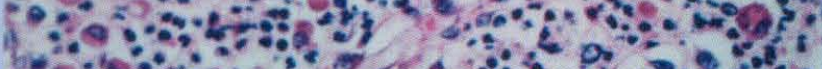

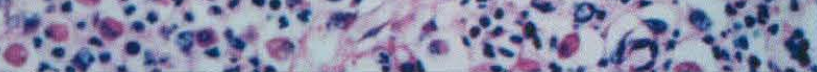
C

Figura 1 - Lesão não neoplásica: Processo inflamatório de caráter crônico. A - Aspecto clínico da lesão em região inguinal; $\mathbf{B}$ Aspecto citológico, coloração de Rosenfeld, 400X; C Aspecto histológico, coloração H\&E, 400X.
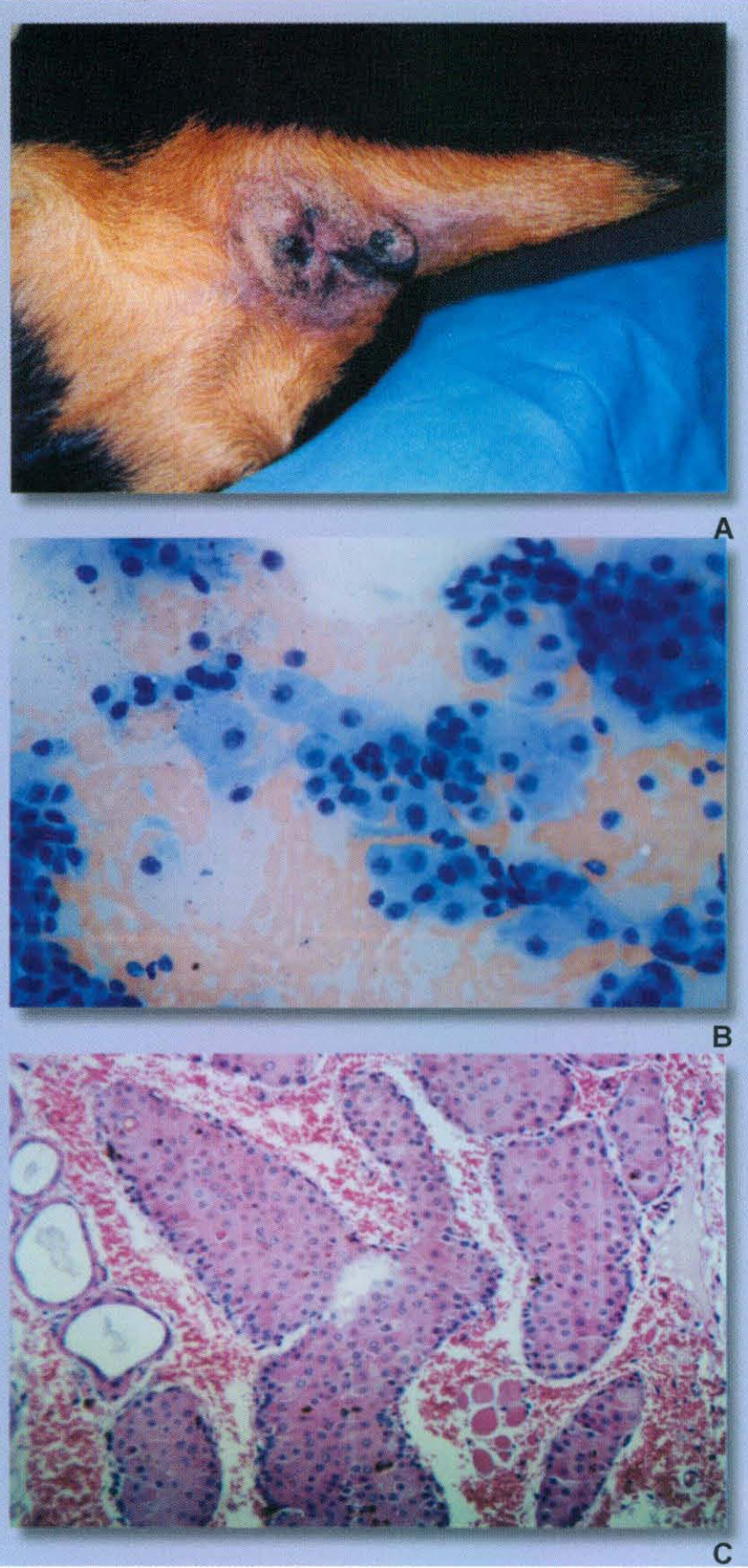

Figura 2 - Neoplasia Epitelial: Adenoma Hepatóide: A - Aspecto clinico da lesão em região perianal; B - Aspecto citológico, coloração de Rosenfeld, 400X; C - Aspecto histológico, coloração H\&E, 200X 
CHALITA, M. C. C.; MATERA, J. M.; ALVES, M. T. S.; LONGATTO FILHO, A. Tumores em pele e partes moles de cães - Estudo clinico e cito-histológico / Canine skin and soft tissue tumors - Clinical and cytohistological study Tumores de piel y partes blandas en perros - Estudio clínico y citohistológico Rev. educ. contin. CRMV-SP / Continuous Education Journal CRMV-SP, São Paulo, volume 5, fasciculo 2, p. 171-180, 2002.

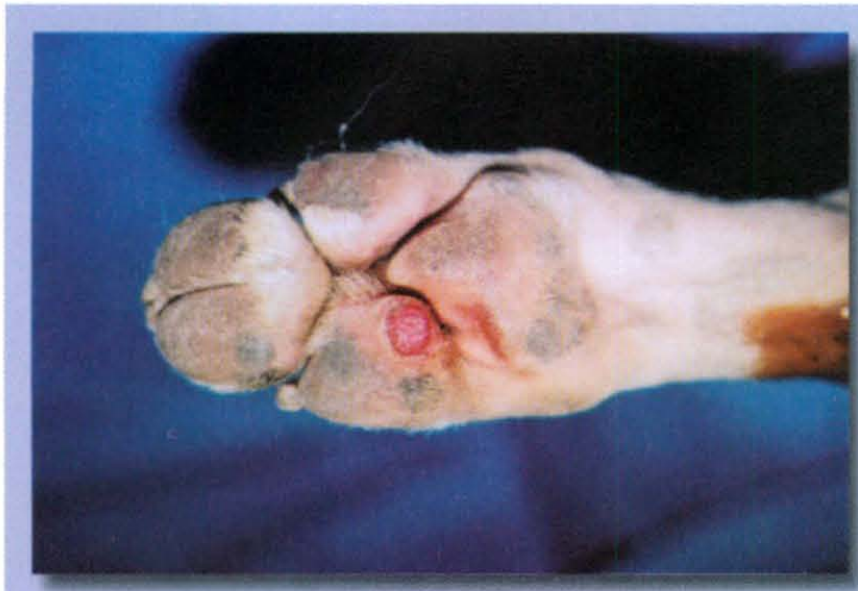

A

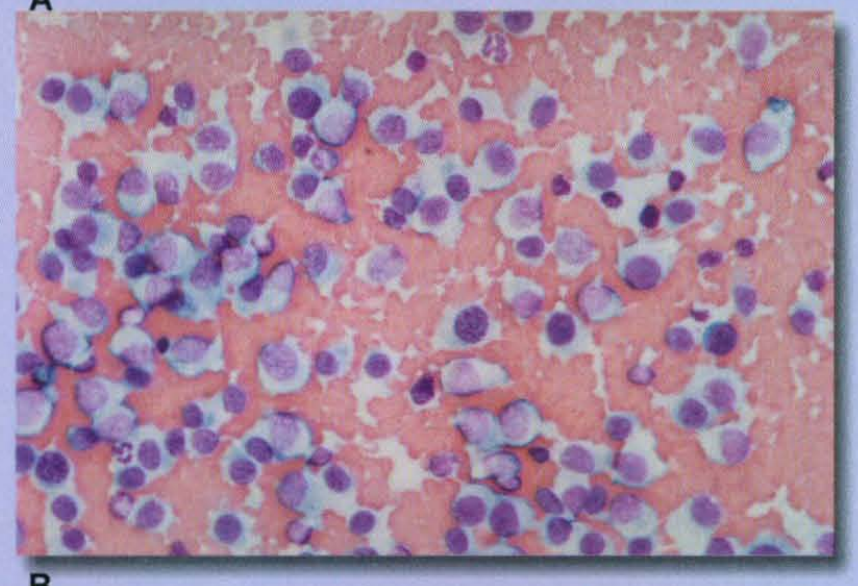

\section{B}

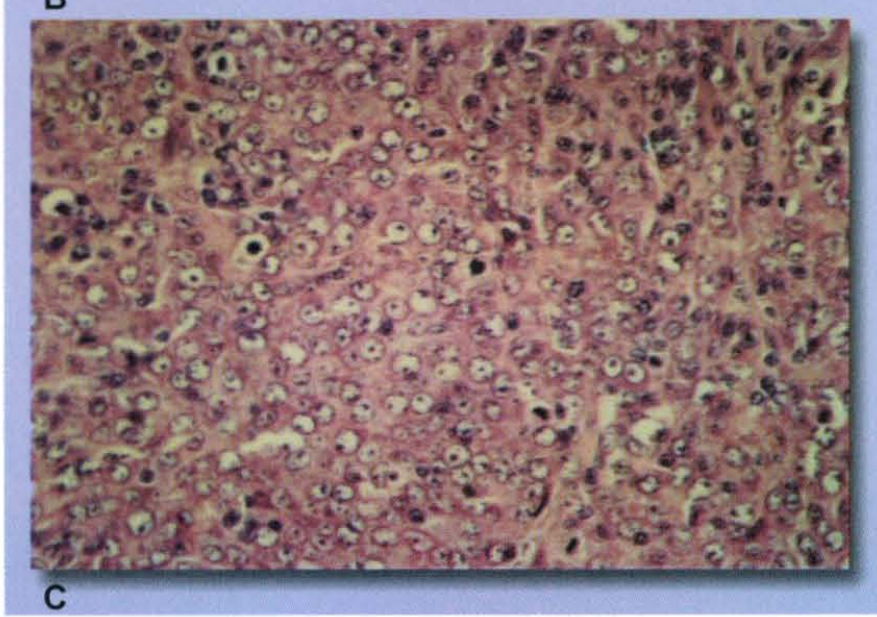

Figura 3 - Neoplasia de Células Redondas: Histiocitoma: A - Aspecto clínico da lesão em região de coxim; B - Aspecto citológico, coloração de Rosenfeld, 400X; C - Aspecto histológico, coloração $\mathrm{H} \& \mathrm{E}, 400 \mathrm{X}$.
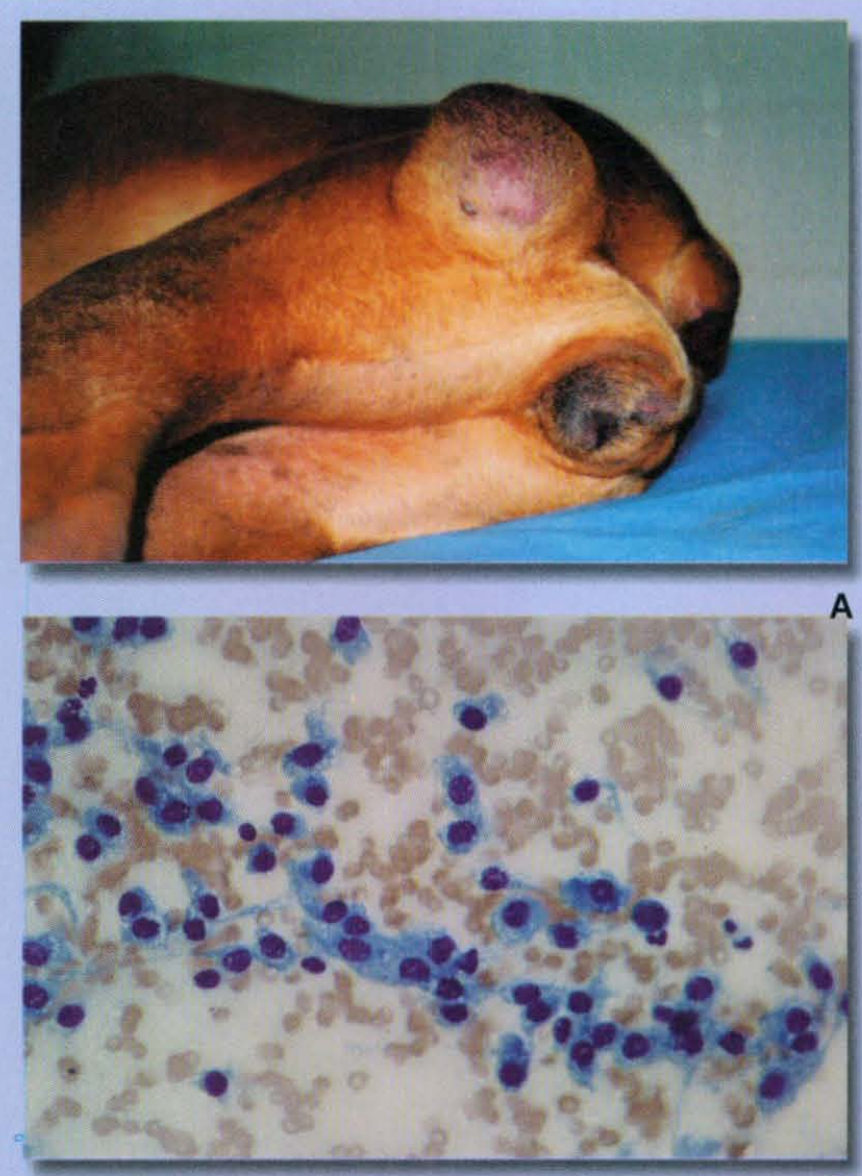

B

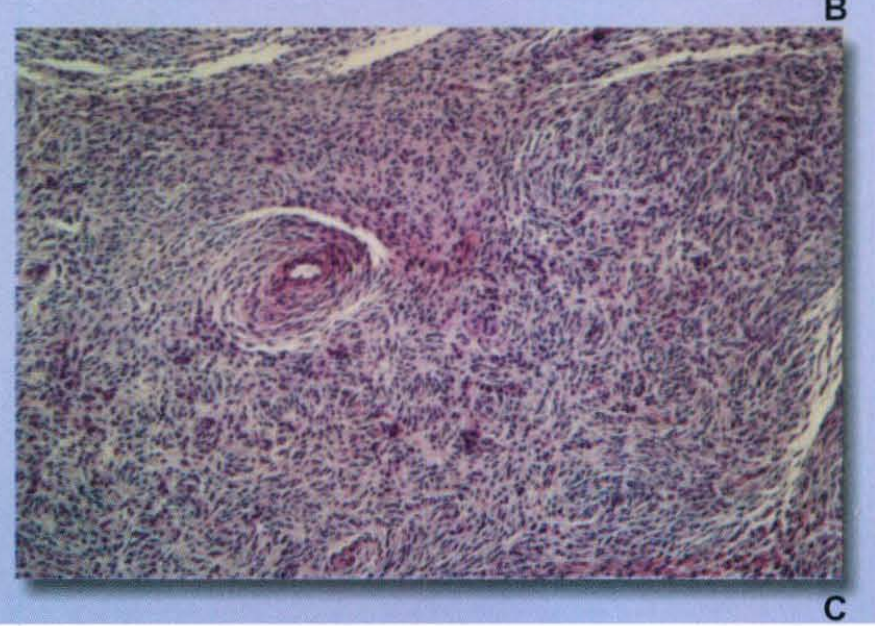

Figura 4 - Neoplasia Mesenquimal: Hemangiopericitoma: A - Aspecto clínico da lesão em membro pélvico; B - Aspecto citológico, coloração de Rosenfeld, 400X; C - Aspecto histológico, coloração H\&E, 100X. 


\section{DISCUSSĀO E CONCLUSŌES}

A alta incidência de tumores que acometem pele e partes moles em cães foi constatada pelo grande número de animais $(n=213)$ atendidos no período de 17 meses. Machos e fềmeas foram igualmente acometidos e aqueles com 6 anos de idade ou mais representaram $75 \%$ dos casos, confirmando dados da literatura mundial (DORN; TAYLOR; SCHNEIDER, 1968; PRIESTER, 1973; CONROY, 1983; HARDY, 1983; HIDAKA, 1985; ER; SUTTON, 1989; MORIELLO; ROSENTHAL, 1990; RUAUX, 1993; VAIL; WITHROW, 1996; WITHROW, 1996). O tempo de evolução das lesões demonstrou não haver qualquer correlação com a presença ou não de malignidade.

Assim como na Medicina Humana, os tumores em pele e partes moles nos animais domésticos devem ser diagnosticados e tratados prontamente.

Sabendo-se que os dados de anamnese e o exame das lesões não são suficientes para afirmar sua natureza, a citologia é o primeiro método diagnóstico indicado pelas inúmeras vantagens que consagradamente apresenta. Ela participa como método de triagem, mas que, por muitas vezes, pode resultar no diagnóstico definitivo do processo.

Os tumores em pele e partes moles, independentemente da presença ou não de malignidade sofrem, na maioria das vezes, intervenção cirúrgica como única ou parte do tratamento. Dessa forma, é compreensível que uma lesão muito grande, em que as possibilidades de retirada cirúrgica completa são mínimas ou inexistentes, pode impedir que seja instituído o tratamento adequado. Assim, mesmo quando de natureza benigna, o que representa aproximadamente $70 \%$ dos casos, o ideal é que a lesão seja retirada cirurgicamente quando ainda com dimensões pequenas e que a conduta equivocada de "esperar para ver se cresce" seja abolida definitivamente .

A técnica de coleta sem aspiração permite uma melhor avaliação da consistência do tumor pelo profissional e uma maior segurança na localização e condução da agulha. Constatou-se, ainda, a grande vantagem da facilidade de retirada imediata do instrumento usado para a coleta, no caso apenas a agulha, protegendo-se tanto o paciente quanto o médico veterinário, caso haja alguma reação inesperada do primeiro.

Não só as informações relativas à característica das amostras coletadas como também às propriedades clínicas das lesões foram indispensáveis para que o diagnóstico citológico fosse mais preciso, já que se tem conhecimento de que informações clínicas incompletas ou erradas podem induzir ao erro diagnóstico (HAJDU; MELAMED, 1984).

Dos 40 casos positivos para malignidade diagnosticados histologicamente, 3 foram negativos ao exame citológico, caracterizando a incidência de $7,5 \%$ de falsos negativos. Esse fato deve-se à desvantagem que o método citológico apresenta em relação ao histológico na avaliação da arquitetura tecidual. A sensibilidade do método citológico estará sempre prejudicada quando da avaliação de neoplasias malignas cujas características morfológicas celulares não são suficientes para suspeitar de malignidade, necessitando da observação de invasão tecidual para tal.

A alta especificidade do método citológico recomenda-o para as aplicações diagnósticas em veterinária, orientando condutas de maneira eficaz, a baixo custo e sem procedimentos pré-cirúrgicos invasivos ou que comprometam clinicamente o animal examinado. Além da alta correlação na discriminação de malignidade, a citologia apresentou um grande potencial de tipificação das lesões em comparação à histologia, reconhecendo a origem histogenética das neoplasias.

O método mostrou-se também muito sensível, o que limita as eventuais críticas quanto à credibilidade dos resultados. Falhas na amostragem podem ser consideradas fatos ocasionais, visto que foi obtida uma taxa de aproveitamento de $94 \%$ ( $7 / 117$ amostras foram inadequadas).

Os resultados citológicos ofereceram, na maioria dos casos, informações preciosas à interpretação histológica, contribuindo para uma maior eficiência do diagnóstico da afecção. Como já proposto anteriormente (URBACH; BURKE; TRAENKLE, 1957; OLGIVIE; MOORE, 1996), também constatou-se que essas informações devem ser somadas sempre que possível, já que um método não exclui o outro e, sim, complementam-se. 


\section{SUMMARY}

Over the course of 17 months, non-aspiration fine needle (21-27G) cytology was performed on 213 dogs with 300 skin and soft tissue tumors. The smears were air dried and stained by the Rosenfeld method. There were 119 males $(56 \%)$ and 94 females $(44 \%)$, the majority of at least 6 years of age $(75 \%)$. Mongrel dogs were over-represented $(n=74)$, followed by Boxer $(n=21)$, Poodle $(n=18)$, German Shepard $(n=15)$, Cocker Spaniel $(n=12)$, and Doberman Pinscher $(n=11)$. In $40 \%$ of the cases ( $85 \mathrm{dogs}, 117$ lesions), histological evaluation was available to compare with the cytologic results. In this group, 77 specimens were benign ( 22 non-neoplastic and 55 neoplastic) and 40 malignant. Tumors were represented by $19 \%$ non-neoplastic lesions, $36 \%$ epithelial tumors, $30 \%$ mesenchymal tumors, $13 \%$ round cell tumors and $2 \%$ melanocytic tumors. The most frequent non-neoplastic lesions were inflammatory processe $(n=9)$ and epidermal cysts $(n=9)$. Lipoma $(n=14)$ and trichoblastoma $(n=14)$ were the most common benign neoplastic lesions. Mast cell tumor $(n=14)$ and hemangiopericytoma $(\mathrm{n}=9)$ represented the most common malignant lesions. When compared to histology, the cytologic examination had $89 \%$ diagnostic sensitivity, $100 \%$ specificity, $100 \%$ positive predictive value, $96 \%$ negative predictive value and $97 \%$ efficacy.

Key words: Neoplasms. Skin. Citology. Histology. Dogs.

\section{RESUMEN}

En el período de agosto de 1998 a diciembre de 1999, 213 perros portadores de 300 tumores de piel y/o de partes blandas fueron evaluados clínicamente, y el material recolectado de las lesiones, con una aguja fina (21-27G), sin aspiración, se sometió a un examen citológico. Los frotis se secaron al aire y se colorearon con la técnica de Rosenfeld. Los perros con seis años de edad o más $(\mathrm{n}=159)$ fueron responsables por el $75 \%$ de los casos; el $56 \%(\mathrm{n}=119)$ de los animales eran machos y el 44\% ( $n=94)$ hembras. Los animales sin raza definida (SRD) $(n=74)$, seguidos de las razas Boxer $(n=21)$, Poodle $(n=18)$, Ovejero Alemán $(n=15)$, Cocker Spaniel $(n=12)$ y Doberman $(n=11)$ fueron los más frecuentes. Al cuarenta por ciento de los perros $(85 / 213)$ se les realizó el examen histológico de los 117 tumores que presentaban. Se encontraron 77 lesiones benignas (22 no neoplásicas y 55 neoplásicas) y 40 malignas. Los tumores estuvieron representados por lesiones no neoplásicas (19\%), neoplasia epitelial (36\%), neoplasia mesenquimal (30\%), neoplasia de célula redonda (13\%) y neoplasia melanocítica (2\%). Las lesiones neoplásicas más frecuentes fueron los procesos inflamatorios con granuloma de cuerpo extraño $(n=9)$ y los quistes epidérmicos $(n=9)$; entre las neoplasias benignas, el lipoma $(n=14)$ y el tricoblastoma $(n=10)$ y, entre las malignas, el mastocitoma $(n=14)$ y el hemangiopericitoma $(n=9)$ fueron las más frecuentes. El método citológico demostró ser bastante eficaz para la evaluación de tumores de piel y partes blandas, con una sensibilidad del $89 \%$, especificidad del $100 \%$, valor predictivo positivo del $100 \%$, valor predictivo negativo del $96 \%$, eficiencia del $97 \%$ en comparación con el examen histológico.

Palabras clave: Neoplasia. Piel. Citología. Histología. Perros. 


\section{REFERÊNCIAS}

ALLEN, S. W.; PRASSE, K. W. Cytologic diagnosis of neoplasia and perioperative implementation. The Compendium on Continuing Education for the Practicing Veterinarian, v. 8, n. 2, p. 72-80, 1986.

BARTON, C. L. Cytologic diagnosis of neoplastic diseases: an algorithm. Texas Veterinary Medical Journal, v. 45, n. 5, p. 1113,1983 .

BARTON, C. L. Cytologic diagnosis of cutaneous neoplasia: an algorithmic approach. The Compendium on Continuing Education for the Practicing Veterinarian, v. 9, n. 1, p. 20-33, 1987.

BOSTOCK, D. E. Neoplasms of the skin and subcutaneous tissues in dogs and cats. British Veterinary Journal, v. 142, n. 1,p. 1-19, 1986.

BOSTOCK, D. E.; OWEN, L. N. A colour atlas of neoplasia in the cat, dog and horse. London: Wolfe Medical, 1975. p. 15-53.

BOTTLES, $K$. et al. Fine needle aspiration biopsy. The American Journal of Medicine, v. 81, n. 3, p. 525-531, 1986.

CAMPBELL, T. W. Comparative avian and mammalian cytodiagnosis - part I. The Compendium on Continuing Education for the Practicing Veterinarian, v. 12, n. 5, p. 702709, 1990.

CONROY, J. D. Canine skin tumors. Journal of the American Animal Hospital Association, v. 19, n. 1, p. 91-114, 1983.

COWELL, R. L.; TYLER, R. D. Cytology of cutaneous lesions. Veterinary Clinics of North America: Small Animal Practice, v. 19, n. 4, p. 769-794, 1989.

DOBSON, J. M.; GORMAN, N. T. A clinical approach to the management of skin tumors in dogs and cats. In Practice, v. 10, n. 2 , p. $55-68,1988$.

DORN, E. R.; TAYLOR, D.; SCHNEIDER, R. Survey of animal neoplasms in Alameda and Contra Costa Counties, California II. Journal of National Cancer Institute, v. 40, n. 2, p. 307-318, 1968.

ELSE, R. Biopsy: special techniques and tissues. In Practice, v. 11, n. 1, p. 27-34, 1989.
ENZINGER, F. M.; WEISS, S. W. Soft tissue tumors. 3.ed. St Louis: Mosby, 1995.

ER, J. C.; SUTTON, R. H. A survey of skin neoplasms in dogs from Brisbane region. Australian Veterinary Journal, v. 66, n. 7, p. 225-227, 1989.

GORMAN, N. T. Neoplasia of the skin and associated tissues. In: ANNUAL WALTHAM/OSU SYMPOSIUM - ONCOLOGY AND HEMATOLOGY, 20., 1996, [S.I.]. Symposium... p. 27-33.

HAJDU, S. I.; MELAMED, M. R. Limitations of aspiration cytology in the diagnosis of primary neoplasms. Acta Cytologica, v. 28, n. 3, p. 337-343, 1984.

HALL, R. L.; MACWILLIAMS, P. S. The cytologic examination of cutaneous and subcutaneous masses. Seminars in Veterinary Medicine and Surgery (Small Animal), v. 3, n. 2, p. 94-108, 1988.

HARDY, W. D. Introduction. Journal of the American Animal Hospital Association, v. 19, n. 1, p. 1, 1983.

HIDAKA, Y. Clinical study of canine cutaneous tumors, especially the incidence and cytological examination of tumors. Japanese Journal of Veterinary Research, v. 33, n. 1 e 2, p. 71, 1985.

JACOBS, R. M. Foreword. Seminars in Veterinary Medicine and Surgery (Small Animal), v. 3, n. 2, p. 83-84, 1988.

KOSS, L. G. Introduction: scope and sampling techniques in diagnostic cytology. In: . Diagnostic cytology and its histopathologic bases. 4.ed. 1992. v. 1, p. 1-11.

LARKIN, H. A. Veterinary cytology - fine needle aspiration of masses or swellings on animals. Irish Veterinary Journal, v. 47, n. 2, p. 65-73, 1994.

LEVER, J. V.; TROTT, P. A.; WEBB, A. J. Fine needle aspiration cytology. Journal of Clinical Pathology, v. 38, n. 1, p. 1-11, 1985.

MEYER, D. J.; FRANKS, P. Clinical cytology-management of tissue specimens. Modern Veterinary Practice, v. 67, n. 3, p. 255-259, 1986. 
CHALITA, M. C. C.; MATERA, J. M.; ALVES, M. T. S.; LONGATTO FILHO, A. Tumores em pele e partes moles de cães - Estudo clinico e cito-histológico / Canine skin and soft tissue tumors - Clinical and cytohistological study/Tumores de piel y partes blandas en perros - Estudio clinico y citohistológico / Rev. educ. contin. CRMV-SP / Continuous Education Journal CRMV-SP, São Paulo, volume 5, fascículo 2, p. 171 - 180, 2002.

MIRALLES, T. G. et al. Fine needle aspiration cytology of softtissue lesions. Acta Cytologica, v. 30, n. 6, p. 671-678, 1986.

MORIELLO, K. A.; ROSENTHAL, R. C. Clinical approach to tumors of the skin and subcutaneous tissues. Veterinary Clinics of North America: Small Animal Practice, v. 20, n. 4, p. 1163-1191, 1990.

OLGIVIE, G. K.; MOORE, A. S. Clinical cytology and neoplasia. In: Managing the veterinary cancer patient: a practice manual. New Jersey: Veterinary Learning Systems, 1996. p. 37-51.

O'ROURKE, L. G. Cytologic techniques: sampling, slide preparation, staining. Modern Veterinary Practice, v. 64, n. 3, p. 185-189, 1983.

PERMAN, V.; ALSAKER, R. D.; RIIS, R. C. Cytology of the dog and cat. American Animal Hospital Association, 1979. 159 p.

PHILIPS, J. N.; GOODMAN, B. N. Clinching the diagnosis: fine needle aspiration cytology. Pathology, v. 19, n. 4, p. 371-376, 1987.

PRIESTER, W. A. Skin tumors in domestic animals. Data from 12 United States and Canadian Colleges of Veterinary Medicine. Journal of National Cancer Institute, v. 50, n. 2, p. 457-466, 1973.

REPPAS, G.; CANFIELD, P. Citología diagnóstica de lesiones cutáneas en el perro y en el gato. Parte I: tratamiento de las muestras para el examen citológico. Veterinary International, v. 7,n. 1, p. 8-17, 1995.

ROGERS, K. S.; BARTON, C. L.; HABRON, J. M. Cytology during surgery. The Compendium on Continuing Education for the Practicing Veterinarian, v. 18, n. 2, p. 153-162, 1996.

RUAUX, C. A clinical approach to canine and feline neoplasia. Australian Veterinary Practitioner, v. 23, n. 1, p. 44-52, 1993.

SANTOS, J. E. C.; LEIMAN, G. Non-aspiration fine needle cytology application of a new technique to nodular thyroid disease. Acta Cytologica, v. 32, n. 3, p. 353-356, 1988.
SCHULTENOVER, S. J. et al. Needle aspiration biopsy: role and limitations in surgical decision making. American Journal of Clinical Pathology, v. 82, n. 4, p. 405-410, 1984.

SEYBOLD, I.; GOLDSTON, R. T.; WILKES, R. D. Exfoliative cytology. Veterinary Medicine, v. 77, n. 7, p. 1029-1033, 1982.

TYLER, R. D. et al. Introduction. In: COWELL, R.L.; TYLER, R.D.; MEINKOTH, J.H. Diagnostic cytology and hematology of the dog and cat. 2 ed. St Louis: Mosby, 1999. p. 1-19.

URBACH, F.; BURKE, E. M.; TRAENKLE, H. L. Cytodiagnosis of cutaneous malignancy. American Medical Association Archives of Dermatology, v. 76, p. 343-350, set. 1957.

VAIL, D. M.; WITHROW, S. J. Tumors of the skin and subcutaneous tissues. In: WITHROW, S. J.; MACEWEN, E. G. Small animal clinical oncology. 2.ed. Philadelphia: W B Saunders, 1996. p. 167-191.

VALLI, V. E. O. Techniques in veterinary cytopathology. Seminars in Veterinary Medicine and Surgery (Small Animal), v. 3, n. 2, p. 85-93, 1988.

VILLIERS, E.; DUNN, J. Collection and preparation of smears for cytological examination. In Practice, v. 20, n. 7, p. 370-377, 1998.

WELLMAN, M. L. The cytologic diagnosis of neoplasia. Veterinary Clinics of North America: Small Animal Practice, v. 20, n. 4 , p. $919-938,1990$.

WELLMAN, M. L. Cytology and the Diagnosis of Neoplasia. In: ANNUAL WALTHAM/OSU SYMPOSIUM - ONCOLOGY AND HEMATOLOGY, 20., 1996, [S.1.]. Symposium... p. 11-20.

WITHROW, S. J. Why worry about cancer in pet animals? In: WITHROW, S. J.; MACEWEN, E. G. Small animal clinical oncology. 2.ed. Philadelphia: W B Saunders, 1996. p. 1-3. 